Abstracta Iranica Iranica

Revue bibliographique pour le domaine irano-aryen

Volume 28 | 2007

Comptes rendus des publications de 2005

\title{
We Are Iran: The Persian Blogs. New York, Soft Skull Press, 2005, $384 \mathrm{p}$.
}

\section{Anicée Van Engeland}

\section{(2) OpenEdition}

1 Journals

\section{Édition électronique}

URL : http://journals.openedition.org/abstractairanica/20221

DOI : 10.4000/abstractairanica.20221

ISSN : 1961-960X

Éditeur :

CNRS (UMR 7528 Mondes iraniens et indiens), Éditions de l'IFRI

Édition imprimée

Date de publication : 15 mai 2007

ISSN : 0240-8910

\section{Référence électronique}

Anicée Van Engeland, « We Are Iran: The Persian Blogs. New York, Soft Skull Press, 2005, 384 p. », Abstracta Iranica [En ligne], Volume 28 | 2007, document 392, mis en ligne le 18 septembre 2007 , consulté le 25 septembre 2020. URL : http://journals.openedition.org/abstractairanica/20221 ; DOI : https://doi.org/10.4000/abstractairanica.20221

Ce document a été généré automatiquement le 25 septembre 2020.

Tous droits réservés 


\title{
We Are Iran: The Persian Blogs. New York, Soft Skull Press, 2005, 384 p.
}

\author{
Anicée Van Engeland
}

1 Ce livre part à la découverte du monde des webloggers iraniens. L'A. prend l'exemple du premier cyber-journaliste iranien Ḥoseyn DeraHšsān pour expliquer l'importance des weblogs pour la liberté d'expression. Tout le mouvement est ainsi analysé : il existe en effet aujourd'hui plus de 64000 blogs, la majorité ayant été créés sur le modèle DeraHšsān. L'A. a entrepris un travail important en visitant une grande majorité de ces sites afin de dresser un portrait fidèle de cet Iran des weblogs, loin des clichés sur la société civile iranienne. Ces weblogs sont utilisés par des journalistes censurés, mais aussi des groupes d'étudiants, des organisations non gouvernementales qui peuvent ainsi collaborer, ou encore des Iraniens qui racontent leur vie quotidienne. Des sujets aussi variés que les droits de la femme, la torture, l'actualité internationale, la vie quotidienne ou encore le droit et la culture y sont abordés sans aucune censure. On découvre un Iran où se mêle réflexions sur la liberté, la culture, la religion et la politique étrangère. Ces auteurs du net dressent ainsi un portrait vivant de "leur " Iran. Ce livre n'est pas seulement un témoignage de l'originalité des voix iraniennes du weblog, il présente aussi l'héritage offert par ces cyber-journalistes dont certains sont arrêtés et emprisonnés. Cet ouvrage permet ainsi de mettre aussi en exergue les méthodes utilisées par le pouvoir judiciaire conservateur pour contrer la société civile. Il s'agit donc d'une véritable source d'information, non seulement pour les cyberjournalistes, mais aussi pour ceux qui désirent connaître les pensées et expériences d'une partie de la population iranienne. Le livre ne présente cependant qu'une petite partie de la population iranienne, celle qui a choisi de lutter en faveur de la liberté d'expression par la voie d'internet. En effet, beaucoup d'Iraniens n'ont pas accès au web ou ont choisi de lutter différemment. 
INDEX

Thèmes : 12.1. Iran

\section{AUTEURS}

ANICÉE VAN ENGELAND

Paris 